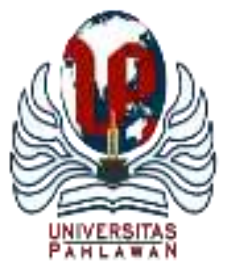

Edukatif : Jurnal Ilmu Pendidikan Volume 4 Nomor 1 Tahun 2022 Halm 917 - 924 EDUKATIF: JURNAL ILMU PENDIDIKAN

Research \& Learning in Education

https:/ledukatif.org/index.php/edukatif/index

\title{
Implementasi Pendidikan Karakter Islam dalam Pembelajaran Pendidikan Agama Islam Masa Pandemi Covid-19 di Sekolah Dasar
}

\author{
Manis Kiptiawati Adha ${ }^{1 凶}$, Astuti Darmiyanti ${ }^{2}$ \\ Universitas Singaperbangsa Karawang, Indonesia ${ }^{1,2}$ \\ E-mail : $\underline{\text { manisadha81@ gmail.com }}^{1}$, astuti.darmiyanti@ fai.unsika.ac.id ${ }^{2}$
}

\begin{abstract}
Abstrak
Pendidikan Agama Islam memainkan peran penting dalam pendidikan karakter di sekolah dasar. Namun seiring merebaknya pandemic Covid-19, internalisasi nilai-nlai pendidikan karakter dalam pembelajaran PAI terpaksa harus beradaptasi dan mengalami beragam perubahan, baik perencanaan, desain, implementasi hingga penilaian dan beralihnya fungsi guru dan orangtua siswa. Penelitian bertujuan menjelaskan pelaksanaan pendidikan karakter dalam pembelajaran PAI selama masa pandemic Covid 19 di sekolah dasar. Penelitian dilaksanakan di SDN Sukaraya 01, kabupaten Bekasi. Penelitian ini mengambil pendekatan deskriptif kualitatif. Pengumpulan data melalui studi wawancara, pengumpulan data melalui observasi dan studi dokumentasi. Hasilnya menunjukkan pembinaan karakter siswa dalam pembelajaran PAI dilaksanakan secara daring menggunakan platform Zoom Meet dan Whatsapp Group. Karakter religius ditanamakan dengan berdoa bersama sebelum dan sesudah pembelajaran, praktik sholat dhuha di rumah, tadarus online berjamaah, dan penanaman nilai-nilai toleransi dalam pembelajaran. Siswa diberikan tugas mandiri maupun kelompok untuk menanamkan sikap mandiri dan gotong royong. Guru menanamkan pentingnya sifat Rasulullah seperti shiddiq, tabligh, Amanah, dan fathonah untuk menanamkan integritas. Dan siswa pun diajarkan cara mencintai budaya dan tanah air sebagai wujud nasionalisme. Guru PAI bersama orangtua berkolaborasi dan saling memperkuat peran dalam mendukung penguatan nilai-nilai pendidikan karakter selama siswa melaksanakan pembelajaran dari rumah (BDR).
\end{abstract}

Kata Kunci: Pendidikan Karakter, PAI, Sekolah Dasar

\begin{abstract}
Islamic Religious Education plays an important role in character education in elementary schools. However, as the Covid-19 pandemic spreads, the internalization of character education values in PAI learning is forced to adapt and undergo various changes, from planning, design, implementation to assessment and the shifting of the functions of teachers and parents. This study aims to explain the implementation of character education in PAI learning during the Covid 19 pandemic in elementary schools. The research was conducted at SDN Sukaraya 01, Bekasi district. This research takes a qualitative descriptive approach. Data collection was through interview studies, data collection through observation, and documentation studies. The results show that the character development of students in PAI learning is carried out online using the Zoom Meet and Whatsapp Group platforms. Religious character is instilled by praying together before and after learning, practicing dhuha prayer at home, online tadarus in the congregation, and inculcating the values of tolerance in learning. Students are given independent or group assignments to instill an attitude of independence and cooperation. The teacher instills the importance of the characteristics of the Prophet such as shiddiq, tabligh, Amanah, and fathonah to instill integrity. And students are also taught how to love culture and the homeland as a form of nationalism. PAI teachers and parents collaborate and strengthen each other's roles in supporting the strengthening of character education values as long as students carry out learning from home (BDR).
\end{abstract}

Keywords: Character Education, Islamic Religious Education, Elementary School

Copyright (c) 2022 Manis Kiptiawati Adha, Astuti Darmiyanti

$\triangle$ Corresponding author:

Email : astuti.darmiyanti@fai.unsika.ac.id

DOI : https://doi.org/10.31004/edukatif.v4i1.2008

ISSN 2656-8063 (Media Cetak)

ISSN 2656-8071 (Media Online)

Edukatif : Jurnal Ilmu Pendidikan Vol 4 No 1 Tahun 2022 p-ISSN 2656-8063 e-ISSN 2656-8071 
918 Implementasi Pendidikan Karakter Islam dalam Pembelajaran Pendidikan Agama Islam Masa Pandemi Covid-19 di Sekolah Dasar - Manis Kiptiawati Adha, Astuti Darmiyanti

DOI: https://doi.org/10.31004/edukatif.v4i1.2008

\section{PENDAHULUAN}

Pandemi virus Corona atau Covid-19 masih menjadi perhatian serius, karena keberadaannya bukan hanya sebatas menjadi masalah kesehatan, tapi telah menimbulkan dampak yang lebih luas dalam berbagai aspek kehidupan, termasuk dalam kehidupan sosial dan ekonomi (Obi et al., 2020), bahkan yang lebih parah adalah berujung pada kejahatann yang terjadi di dunia maya (Kashif et al., 2020). Kekhawatiran ini menyebabkan kecemasan di tengah masyarakat, terutama saat berada di lingkungan keramaian. Pandemi Covid-19 menyebabkan krisis global yang masif. Bahkan pandemi Covid-19 berdampak pada hampir semua aspek tatanan kehidupan, termasuk dunia pendidikan.

Selama kondisi pandemi, peran dan posisi pendidikan menjadi aspek yang sangat krusial (Mithhar et al., 2021). Menanggapi hal ini, Kementerian Pendidikan Republik Indonesia mendukung dan mengintruksikan secara tegas pengajaran berbasis teknologi informasi dan peningkatan kapasitas layanan platform pembelejaran jarak jauh untuk mendukung pengajaran online di sekolah (Putra et al., 2020). Seketika ruang kelas online telah menjadi kebutuhan cara untuk menjaga ketertiban pengajaran normal (Hatta et al., 2020). Pandemi Covid-19 memaksa sekolah dan pendidikan untuk terlibat dalam transformasi proses pembelajaran (Setiawan et al., 2021).

Pembelajaran online telah menjadi kebijakan yang diberlakukan di seluruh sekolah dasar di Indonesia (Abidah et al., 2020). Penerapan pembelajaran jarak jauh di masa pandemi Covid-19 menimbulkan berbagai permasalahan terutama pada pembangunan karakter di sekolah. Pendidikan karakter siswa merupakan hal penting yang bisa saja terabaikan dalam pembelajaran online. Bahkan dalam praktiknya, pendidikan karakter terdistorsi oleh kondisi pembelajaran online selama diberlakukannya belajar dari rumah.

Pendidikan karakter penting dilaksanakan di sekolah mengingat semakin maraknya tindakan degradasi moral generasi muda. Melalui pembelajaran pendidikan agama Islam, SDN Sukaraya 01 kabupaten Bekasi konsisten melaksanakan pendidikan karakter Islam melalui pembelajaran agama Islam. Mata pelajaran PAI sangat strategis dalam mengimplementasikan pendidikan karakter karena ada di semua jenjang pendidikan dari pendidikan usia dini hingga perguruan tinggi (Septiani \& Taufik, 2021). Pendidikan karakter tidak dititik beratkan pada mata pelajaran tertentu, tetapi diintegrasikan pada seluruh mata pelajaran baik secara daring maupun pembelajaran online (Prastitasari, 2021). Karakter yang dikembangkan selain mengacu pada nilainilai PPK, juga didasarkan pada nilai-nilai pendidikan akhlak Rasulullah mencakup shiddiq, fathonah, amanah, dan tabligh.

Pertanyaan yang muncul selanjutnya adalah, bagaimana mengimplementasikan pendidikan karakter Islam melalui pembelajarn PAI di sekolah secara daring pada masa pandemi covid-19 termasuk tantangan dan solusi atau bahkan peluang. Sampai hari ini, sebagian besar orang Indonesia masih berparadigma bahwa ruang kelas luring sebagai pendidikan yang layak. Orang masih berpikir bahwa ruang kelas adalah sekolah nyata dan kelas online dinilai kurang efektif (Hidayat et al., 2021).

Pembelajaran PAI dituntut harus mampu mendorong siswa untuk menumbuhkan nilai-nilai penguatan pendidikan karakter (PPK) (Maisaro et al., 2018). Demikian pula kendati secara daring/online pembelajaran, melalui PAI SDN Sukaraya 01 senantiasa mengoptimalkan penanaman karakter kepada siswa. Pembelajaran online harus memfasililtasi siswa untuk menumbuhkan nilai-nilai kejujuran, kemandirian, dan tanggung jawab (Ainiyah, 2013). Pendidikan karakter melalui PAI secara online perlu memeprtimbangkan keterlibatan orang tua dan lingkungan sebagai mitra sekolah. Nilai-nilai karakter yang baik yang dikonsep, diketahui, dirasakan, dan dicintai siswa dapat dilakukan melalui keteladanan yang ditampilkan oleh guru dan orang tua (Efendy, 2018). Selama proses pembelajaran online, kebiasaan atau budaya yang baik akan menjadi kebiasaan bagi siswa dan guru untuk memperkuat internalisasi nilai-nilai karakter dalam pembelajaran pendidikan Islam. Selain itu, guru perlu memperkuat nilai-nilai karakter seperti memberi panggilan, himbauan, dan motivasi 
919 Implementasi Pendidikan Karakter Islam dalam Pembelajaran Pendidikan Agama Islam Masa Pandemi Covid-19 di Sekolah Dasar - Manis Kiptiawati Adha, Astuti Darmiyanti

DOI: https://doi.org/10.31004/edukatif.v4i1.2008

dalam proses pembelajaran bahkan pemberian reward dan punishment sebagai bagian dari penguatan karakter (Cece, 2019).

Pendidikan karakter idealnya dilakukan dalam kondisi pembelajaran tatap muka (Firmansyah et al., 2021). Dalam kondisi normal, internalisasi pendidikan karakter dalam proses pembelajaran dapat dilakukan secara maksimal. Maka tak heran jika muncul beragam kendala dan permasalahan pendidikan karakter secara daring baik dari segi kompetensi guru dan siswa, fasilitas, dan aspek pembelajaran lainnya (Hutauruk \& Sidabutar, 2020). Santika (2020) dalam penelitiannya menjelaskan pembelajaran daring dan jarak jauh, menghadirkann tugas, peran, fungsi dan tanggungjawab juga tantangan ekstra bagi guru agar mampu menghadirkan lingkungan pembelajaran yang kondusif dalam mengembangkan etika, tanggungjawab dan karakter pada siswa. Karena teknik evaluasi dari pendidikan karakter salah satunya dengan cara melakukan observasi langsung agar guru dapat mengamati sikap atau perubahan sikap baru yang muncul pada diri peserta didik (Selegi, 2020). Belum lagi kendala yang dihadapi guru dalam penerapan pembelajaran daring misalnya penguasaan teknologi, kendala jaringan internet dan inovasi pengintegrasian pendidikan karakter pada pembelajran daring yang seolah baru booming manakala pandemi Covid-19 terjadi.

Pembelajaran PAI di sekolah dasar memuat keseimbangan antara kompetensi sikap, pengetahuan, dan keterampilan. PAI memegang peran strategis pembentukan karakter siswa baik kondisi normal maupun selama diberlakukannya belajar dari rumah secara online di masa pandemic. Berdasarkan permasalahan di atas tujuan penelitian ini mengidentifikasi dan mendeskripsikan pendidikan karakter dalam pembelajaran PAI secara online/daring masa pandemi Covid-19 di sekolah dasar. Penelitian berupaya memotret gambaran pendidikan karakter ditinjau dari perangkat pembelajaram, metode pembelajaran, Kegiatan belajar mengajar, dan evaluasi.

\section{METODE PENELITIAN}

Penelitian ini bertujuan untuk mendeskripsikan nilai-nilai karakter yang diajarkan dan tantangan yang dihadapi guru PAI dalam mengimplementasikan pendidikan karakter dalam proses pembelajaran online di SDN Sukaraya 01, kabupaten Bekasi. Metode yang digunakan dalam penelitian ini adalah metode kualitatif dengan pendekatan studi kasus (Suharsaputra, 2012). Dalam penelitian ini, peneliti menggunakan desain studi kasus. Studi kasus adalah studi berbentuk empiris yang bertujuan untuk menganalisis fenomena yang terkait dengan konteks realitas kehidupan. Pendekatan kualitatif dalam bentuk studi kasus cocok untuk menjawab pertanyaan "bagaimana" dan "mengapa" (Prihatsanti et al., 2018). Pengumpulan data dilakukan melalui wawancara, dokumentasi, dan observasi langsung pembelajaran PAI secara online melalui Google Meet dan grup WhatsApp.

Analisis yang akan dilakukan dalam penelitian ini adalah analisis deskriptif kualitatif, yaitu analisis yang menekankan pada pendeskripsian objek penelitian secara rinci terutama mengenai rumusan yang telah ditetapkan, sehingga analisis ini akan menghasilkan suatu kesimpulan dari penafsiran (Setyosari, 2013). Teori yang menjadi dasar penelitian akan dihubungkan secara simultan dengan data lapangan. Dalam mengelola data dan menganalisisnya, penyusun menggunakan metode deduktif, yaitu analisis yang dimulai dari data umum dan kemudian menarik kesimpulan khusus (Hanum, 2013).

\section{HASIL DAN PEMBAHASAN PENELITIAN}

\section{Perencanaan Pendidikan Karakter Islam Dalam Pembelajaran PAI}

Perencanaan pembelajaran memiliki pengaruh yang sangat besar bagi kesuksesan pembelajaran. Tanpa perencanaan yang baik, maka pembelajaran akan berjalan tanpa arah dan tujuan yang jelas (Sufiati \& Afifah, 2019). Ini sejalan dengan pendapat Dewi \& Sadjiarto, (2021) perencanaan menjadi hal wajib yang harus dikuasai oleh guru PAI dalam merancang pendidikan karakter. Dengan demikian perangkat pembelajaran sudah menjadi bagian dari rancangan program pendidikan karakter yang wajib dilakukan oleh guru. 
920 Implementasi Pendidikan Karakter Islam dalam Pembelajaran Pendidikan Agama Islam Masa Pandemi Covid-19 di Sekolah Dasar - Manis Kiptiawati Adha, Astuti Darmiyanti

DOI: https://doi.org/10.31004/edukatif.v4i1.2008

Terkait perencanaan, berdasarkan wawancara dengan kepala sekolah guru PAI SDN SUKARAYA 01 kabupaten Bekasi, Guru wajib membuat perangkat pembelajaran lebih dulu seperti dokumen analisis KI-KD, silabus, prota, promes, kalender akademik, dan rencana pelaksanaan pembelajaran atau RPP. Guru PAI menyusun RPP secara sederhana disesuaikan dengan kurikulum darurat Covid-19. RPP yang digunakan adalah RPP satu lembar namun harus mengintegrasikan nilai-nilai pendidikan karakter ke dalam RPP. Guru juga mencantumkan media online yang digunakan dalam pembelajaran yaitu Whatsapp, Google Classrom, dan Googlemeet.

Guru PAI mengaku tidak terdapat kendala atau kesulitan dalam menyusun perencanaan pembelajaran karena RPP 2013 terbaru hanya mengintrusikan RPP dalam satu lembar. Namun yang perlu diperhatikan dalam perencanaan pendidikan karakter adalah menyusun materi, alokasi waktu dan evaluasi yang tepat dalam menilai karakter siswa. Sejauh ini, dengan kurikulum 2013 pendidikan karakter selalu harus termuat dalam perangkat yang disusun. Dari 4 kompetensi inti (KI), karakter telah diakomodir dalam KI 1 dan KI 2 yaitu karakter religius dan sosial. Capaian karakter yang diharapkan menyesuaikan apa yang sudah digaruskan melalui KI 1 dan KI 2 tersebut ditambah dengan menginternalisasikan nilai-nilai karakter Islam Rasulullah. Sejalan adanya kebijakan Pepres Nomor 87 tahun 2018 tentang Penguatan Pendidikan Karakter, terdapat 5 nilai karakter yang harus diintegrasikan dalam perencanaan pembelajaran yaitu religius, nasionalis, integritas, mandiri dan gotong royong ditambah dengan shiddiq, amanh, tabligh dan fathonah kepada siswa.

\section{Pelaksanaan Pendidikan Karakter Islam dalam Pembelajaran PAI}

Pembelajaran PAI di masa pandemik membutuhkan pola baru dalam penyelenggaraan pembelajaran. Apabila di masa sebelum pandemic dalam kondisi normal, pembelajaran PAI dilaksanakan secara tatap muka namun dalam masa covid interaksi harus secara online yang menuntut skill dan inovasi dalam menyampaikan pembelajaran.

Pelaksanaan pendidikan karakter dalam pembelejaran PAI adalah berupa penanaman nilai-nilai penguatan pendidikan karakter Islam yang diintegrasikan dalam proses pembelajaran daring/online. Sopiah (2021) menjelaskan bahwa selama masa pandemic pemerintah memberlakukan belajar dari rumah, maka guru dituntut berinovasi dalam menanamkan karakter kepada siswa melalui pembelejaran daring. Adapun Media yang digunakan dalam pembelajaran PAI adalah Whatsapp Group, Google Classroom dan G-Meet. Media tersebut dipilih karena dapat mendukung pembelajaran secara synchronous maupun asynchronous. Whatsapp digunakan untuk berkomunikasi, berdiskusi, dan menyampaikan informasi. Googleclassroom digunakan untuk menyampaikan tugas dan pengumpulannya. Adapun Googlemeet untuk tatap muka dan pembelejaran secara synchronous.

Nilai karakter yang diinternalisasikan adalah sebagaimana Perpres Nomor 87 tahun 2018 tentang Penguatan Pendidikan Karakter yaitu religius, nasionalis, integritas, mandiri dan gotong royong (Sutisna et al., 2019). Religius, guru menanamkan kepada siswa mengenai keimanan, ketauhidan, toleransi beragama, ukhuwah Islamiyah, sifat shiddiq, dan anti bullying. Nasionalis, guru menanamkan kepada siswa untuk mencintai Indonesia, mengenal Pancasila sebagai falsafah bangsa, menjaga linglungan, hidup disiplin, dan mencintai keanekaragaman agama, suku dan budaya bangsa. Mandiri, guru mengajarkan kepada siswa untuk semangat dalam menuntut ilmu, kreatif, dan pantang menyerah. Integritas, guru menanamkan dan mengingatkan siswa untuk selalu menjunung kejujuran, anti korupsi, berlaku adil, dan tanggung jawab. Gotong royong, siswa dengan dibimbing guru mengembangkan sikap untuk mau saling menghargai, kerja sama, komitmen atas keputusan bersama, musyawarah mufakat, tolong menolong, dan solidaritas.

Apabila ditinjau secara mendalam, nilai nilai yang ditanamkan dalam pengatan pendidikan karakter bersandar pada nilai-nilai akhlak utama Rasulullah saw yaitu shiddiq, amanah, fathonah dan tabligh. Hal ini karena pada hakikatnya PPK dikembangkan berdasarkan nilai-nilai agama dan kearifan lokal bangsa Indonesia termasuk akhlak dalam Islam. Guru PAI selalu mengingatkan siswanya untuk belajar mandiri, salah satunya dengan membaca buku yang telah disediakan oleh guru PAI dalam bentuk e-book yang di share 
921 Implementasi Pendidikan Karakter Islam dalam Pembelajaran Pendidikan Agama Islam Masa Pandemi Covid-19 di Sekolah Dasar - Manis Kiptiawati Adha, Astuti Darmiyanti

DOI: https://doi.org/10.31004/edukatif.v4i1.2008

melalui WhatsApp. Itu juga merupakan bentuk tanggung jawab sebagai seorang siswa untuk terus belajar. Guru juga selalu mengingatkan siswa untuk jujur dalam mengerjakan tugas yang diberikan yaitu tidak mengcopy paste dari temannya. Salah satu perilaku ketidakjujuran adalah copy-paste dalam mengerjakan tugas dan tes.

Nilai karakter yang juga tampak dominan diberikan oleh guru adalah integritas dan kedisiplinan. Guru PAI sejak awal mengatakan kepada murid-muridnya bahwa "tugas harus diserahkan sesuai dengan waktu yang ditentukan." Guru memberikan penghargaan kepada siswa ketika siswa mengerjakan tugas tepat waktu, yaitu dengan menambahkan skor untuk hasil tugas. Bahkan guru juga memberikan hukuman berupa pengurangan skor hasil tugas jika siswa terlambat menyerahkan tugas. Guru menggunakan metode punishment dan reward untuk memberikan motivasi. Reward and punishment sebagai alat pendidikan diberikan Ketika seorang anak melakukan sesuatu yang baik atau suatu target telah tercapai.

Dalam teori belajar yang dikenal dengan istilah Law of effect, hubungan stimulus-respons cenderung menguat jika hasilnya menyenangkan dan melemah jika hasilnya tidak memuaskan. Efek yang tidak menyenangkan dirasakan seperti hukuman. Sebaliknya, efek yang menyenangkan dirasakan sebagai Rewards. Misalnya, apabila ada siswa tidak dapat mengerjakan tugas karena tidak memiliki kuota internet, guru mengajak siswa untuk membantu teman sekelasnya yang kesulitan. Ini membantu menanamkan empati dan karakter peduli.

Guru PAI intens memanfaatkan Google Meet dan WhatsApp dalam proses pembelajaran online. Guru mengontrol postingan yang ditulis siswa dalam kelompok belajar untuk menanamkan karakter santun dalam berbicara dan bertanggung jawab atas semua perkataan dan tindakan siswa. Terkadang tanpa disadari, beberapa siswa menulis atau mengetik di grup chat WhatsApp dengan menggunakan kata-kata yang tidak sopan, padahal ditujukan kepada temannya. Guru langsung menegurnya dengan kata-kata yang lembut melalui tulisan di grup WhatsApp. Selama proses pembelajaran online menggunakan Google Meet, guru PAI juga mengontrol pakaian siswa, seperti apakah siswa memakai kaos atau tidak? Apakah kamera video dihidupkan atau tidak? Guru akan segera mengingatkan siswa yang memakai pakaian yang tidak pantas atau yang kameranya tidak diaktifkan. Guru PAI juga berpesan agar siswa senantiasa melaksanakan shalat 5 waktu dalam sehari semalam, belajar Al-Qur'an. Bahkan guru akan meminta siswa untuk memberikan rekaman suara siswa yang sedang mengaji. Guru PAI juga akan menanyakan kepada siswa apa yang telah mereka baca tentang materi pelajaran PAI di rumah. Hal itu sebagai bentuk mengingatkan siswa akan tanggung jawabnya sebagai siswa.

\section{Tantangan Implementasi Pendidikan Karakter Islam pada mata pelajaran PAI}

Pendidikan karakter adalah pendidikan yang berkaitan dengan kualitas intrinsik manusia seutuhnya, baik kepribadian, watak, perangai, bakat, interaksi manusia dengan Tuhan, manusia interaksi dengan orang lain, dan interaksi manusia dengan lingkungan sekitarnya (Djaswidi Al Hamdan, 2014). Penerapan pendidikan karakter melalui pembelajaran PAI secara online di masa pandemic COVID-19 memiliki tantangan dibandingkan dengan proses pembelajaran offline dalam kondisi normal.

Pembelajaran PAI secara online berdampak pada kurangnya pengawasan terhadap perkembangan karakter siswa karena tidak adanya interaksi langsung antara guru dengan siswa. Dalam pembelajaran online, guru tidak dapat secara langsung mengontrol karakter siswa. Itulah salah satu kendala dalam menanamkan nilai-nilai karakter meskipun orang tua mendampingi mereka. Hal tersebut berbeda dengan pembelajaran tatap muka, dimana guru dapat mengontrol secara langsung agar siswa dapat memahaminya dengan lebih baik.

Pada pembelejaran daring, siswa kehilangan teladan guru. Peran guru dalam upaya mengimplementasikan pendidikan karakter siswa di sekolah sangat besar. Guru menjelma sebagai contoh atau panutan bagi siswa dalam bertingkah laku. Secara langsung atau tidak langsung, semua tindak tutur guru akan 
922 Implementasi Pendidikan Karakter Islam dalam Pembelajaran Pendidikan Agama Islam Masa Pandemi Covid-19 di Sekolah Dasar - Manis Kiptiawati Adha, Astuti Darmiyanti

DOI: https://doi.org/10.31004/edukatif.v4i1.2008

mempengaruhi perilaku siswa. Minimnya interaksi langsung dan keterbatasan waktu dalam pembelajaran online menyebabkan guru kurang optimal dalam mengawasi perkembangan karakter siswa.

Dengan diintrusikan dan dipromosikannya pembelajaran online dari rumah, proses pendidikan karakter dalam pembelajaran PAI yang semula harus dilakukan berdasarkan kontrol guru. Di masa pandemi seperti ini, guru tidak bisa memantau perkembangan siswa secara maksimal. Orang tua siswa juga harus mengawasi pembelajaran online yang dilakukan siswa di rumah, nemun terkadang mereka para orangtua justru tidak mengontrolnya. Itulah yang terkadang menjadikan siswa kesulitan menemukan kemandirian sehingga kesulitan dalam mengatur waktu belajarnya.

Pembelajaran online seharusnya menjadi kesempatan bagi orang tua untuk mengontrol anaknya. Padahal proses pembelajaran online membutuhkan kerjasama guru dan orang tua siswa. Efektivitas pembelajaran online menuntut guru dan orang tua untuk mengawasi siswa dalam belajar. Orang tua siswa juga harus membagi waktu antara bekerja, mengurus rumah, dan mengawasi belajar anak. Namun yang terjadi adalah guru mengirimkan tugas, dan orang tua mengirimkan pekerjaan anak tanpa pengawasan dalam pembelajaran. Orang tua percaya bahwa tugas sudah dikirim ke guru, kemudian selesai kegiatan belajar untuk hari itu. Hal ini menghasilkan arah komunikasi, tanpa studi pengawasan internal dari orangtua sebaagi tripusat pendidikan.

Masalah teknis dalam pembelajaran online sering dihadapi oleh guru PAI, seperti masalah jaringan internet. siswa dan orang tua terkadang mengeluhkan gangguan jaringan yang lambat bahkan sinyal yang hilang. Diperparah pula dengan kondisi ekonomi orangtua siswa yang kesulitan membeli kuota, maka tak jarang muncul keluhan mengenai kuota internet yang juga sering dikeluhkan oleh siswa dan orang tua siswa. Kebutuhan akan koneksi internet menjadi hal yang signifikan dalam pelaksanaan pembelajaran online. Meski demikian, kenyataan di lapangan membuktikan bahwa banyak siswa mengeluhkan jaringan internet. Pembelajaran PAI di SDN SUKARAYA 01 kabupaten Bekasi memanfaatkan whatsapp dan google classroom. Aplikasi tersebut tidak membutuhkan kuota internet yang besar untuk mengaksesnya bahkan pemerintah memfasilitasi kuota belajar bagi siswa yang mendukung koneksi untuk aplikasi whatsapp dan Google Classroom.

Banyak permasalahan yang dihadapi guru sebagai pendidik dalam menumbuhkn Krajter Islam pada siswa yang teridentifikasi dalam beberapa indikator, antara lain proses penyampaian materi pembelajaran, proses interaksi dengan siswa dalam proses pembelajaran, kualitas pemberdayaan fasilitas, dan unsur-unsur dalam pembelajaran, mengelola bahan ajar yang akan disampaikan dalam proses pembelajaran, dan perangkat kurikulum yang mengikuti kondisi saat ini (kurikulum darurat).

Proses pembelajaran online idealnya tetap dapat mengakomodir kebutuhan belajar siswa untuk mengembangkan bakat dan minatnya sesuai dengan jenjang pendidikannya. Perlu menyiapkan tenaga pendidik, kurikulum yang sesuai, ketersediaan sumber belajar, dan perangkat serta dukungan jaringan yang stabil sehingga komunikasi antara siswa dan pendidik dapat berjalan efektif. Kondisi.

Pembelajaran online belum bisa disebut ideal karena masih terdapat berbagai kendala yang muncul yang dihadapi. Kendala tersebut sekaligus menjadi tantangan dalam pelaksanaan pembelajaran online, mengingat pembelejaran daring merupakan suatu keharusan agar kegiatan pendidikan tetap dapat terselenggara di masa darurat pandemi Covid-19 saat ini. Kendala dan tantangan dalam pelaksanaan pembelajaran online antara lain terkait kesiapan sumber daya manusia, ketidakjelasan arahan pemerintah daerah, belum adanya kurikulum yang sesuai, dan terbatasnya sarana dan prasarana khususnya dukungan teknologi. dan jaringan internet. Kesiapan sumber daya manusia meliputi pendidik, siswa, dan dukungan orang tua, merupakan bagian terpenting dari pelaksanaan pembelajaran online.

Pendidikan karakter Islam dalam pembelejaran PAI secara online dinilai efektif menumbuhkan karakter shiddiq, amanah, fathonah dan tabligh kepada siswa. Meskipun pada beberapa aspek masih belum optimal bahkan memerlukan perbaikan dan keberlanjutan, namun melalui nilai-nilai PPK, karakter rasululah 
923 Implementasi Pendidikan Karakter Islam dalam Pembelajaran Pendidikan Agama Islam Masa Pandemi Covid-19 di Sekolah Dasar - Manis Kiptiawati Adha, Astuti Darmiyanti

DOI: https://doi.org/10.31004/edukatif.v4i1.2008

diintegrasikan dalam pelajaran PAI di kelas secara online melalui diskusi, penyampaian materi, penugasan, dan aktivitas lainnya memanfatkan whatsapp dan Google Classroom.

\section{KESIMPULAN}

Pendidikan karakter Islam di SDN SUKARAYA 01 kabupaten Bekasi merupakan bagian integral dari proses pembelajaran. Di tengah mayoritas masyarakat muslim, nilai-nilai akhlak Rasulullah yang mencakup sifat shiddiq, amanah, fathonah dan tabligh harus tetap diintegrasikan dalam pembelajaran PAI. Kendati dalam eterbatasan, pembelajaran online harus tetap mendukung interaksi siswa-guru secara maksimal sehingga banyak nilai karakter yang dapat diterapkan. Beberapa nilai karakter yang dapat diterapkan oleh guru mengacu pada penguatan pendidika karakter yaitu religius, nasionalis, integrtitas, mandiri dan gotong royong. Pada tahap internalisasi nilai-nilai PPK diintegrasikan pula dengan nilai akhlak Rasululllah dalam pembelejaran PAI secara online. Implementasinya dapat dilakukan melalui metode mandiri, mengontrol seberapa banyak materi yang telah dibaca oleh siswa, memberikan nilai tambahan sebagai reward dan mengurangi nilai tugas sebagai hukuman, mengawasi percakapan siswa di grup WhatsApp dan Google Meet dalam menerapkan nilai-nilai karakter santun dalam memberikan nasehat. Beberapa tantangan yang dihadapi guru PAI dalam menerapkan nilai-nilai karakter dalam PAI pembelajaran diantaranya kurang optimalnya pengawasan terhadap siswa karena kurangnya interaksi dan keterbatasan waktu untuk pembelajaran online. Kurangnya pengawasan dari orang tua sehingga penerapan nilai karakter dalam pembelajaran online PAI belum bisa maksimal. Perlu adanya kerjasama dengan guru dan orang tua dalam pembelajaran di rumah. Masalah teknis seperti internet jaringan, kuota internet, dan ponsel yang rusak menjadi tantangan yang harus dihadapi dan dicartikan solusi dalam pembentukan karakter melalui pembelejaran PAI secara online.

\section{DAFTAR PUSTAKA}

Abidah, A., Hidaayatullaah, H. N., Simamora, R. M., Fehabutar, D., \& Mutakinati, L. (2020). The Impact of Covid-19 to Indonesian Education and Its Relation to the Philosophy of "Merdeka Belajar." Studies in Philosophy of Science and Education, 1(1), 38-49. https://doi.org/10.46627/sipose.v1i1.9

Ainiyah, N. (2013). Pembentukan Karakter Melalui Pendidikan Agama Islam. Al-Ulum, 13(1), 25-38.

Cece. (2019). Penguatan Pendidikan Karakter Melalui Kearifan Lokal Berbasis Al-Qur'an (Implementasi di SMAN Kabupaten Purwakarta) [Strengthening Character Education through Al-Qur'an-Based Local Wisdom (Implemented at SMAN Purwakarta Regency)]. Deepublish.

Dewi, T. A. P., \& Sadjiarto, A. (2021). Pelaksanaan Pembelajaran Daring Pada Masa Pandemi Covid-19. Jurnal Basicedu, 5(4), 1909-1917. https://doi.org/10.31004/basicedu.v5i4.1094

Djaswidi Al Hamdan. (2014). The Character Education In Islamic Education Viewpoint. Jurnal Pendidikan Islam JPI, l(1).

Efendy, H. (2018). Manajemen Pembelajaran dalam Penjaminan Mutu Pendidikan (Studi Multi Situs di SMA Negeri 1 dan SMA Negeri 3 Pamekasan). Jurnal Fikrotuna: Pendidikan Dan Manajemen Islam, 8(1), $1001-1010$.

Firmansyah, F., Taufik, M., Kejora, B., \& Karawang, U. S. (2021). EDUKATIF: JURNAL ILMU PENDIDIKAN Studi Analisis Pemanfaatan Whatsapp dalam Pembelajaran Daring Akidah Akhlak pada Siswa Madrasah Aliyah. 3(5), 2886-2897.

Hanum, N. S. (2013). Keefetifan e-learning sebagai media pembelajaran (studi evaluasi model pembelajaran e-learning SMK Telkom Sandhy Putra Purwokerto). Jurnal Pendidikan Vokasi, 3(1), 90-102. https://doi.org/10.21831/jpv.v3i1.1584

Hatta, P., Aristyagama, Y. H., Yuana, R. A., \& Yulisetiani, S. (2020). Active Learning Strategies in Synchronous Online Learning for Elementary School Students. IJIE (Indonesian Journal of Informatics Education), 4(2), 86. https://doi.org/10.20961/ijie.v4i2.46019 
924 Implementasi Pendidikan Karakter Islam dalam Pembelajaran Pendidikan Agama Islam Masa Pandemi Covid-19 di Sekolah Dasar - Manis Kiptiawati Adha, Astuti Darmiyanti

DOI: https://doi.org/10.31004/edukatif.v4i1.2008

Hidayat, W., Dewi, P., \& Nurdiana, Y. (2021). Strengthening the Character Values in the Online Learning Process Wahyu. Ndonesian Journal of Islamic Education Studies (IJIES), 4(2), 150-164.

Hutauruk, A., \& Sidabutar, R. (2020). Kendala pembelajaran daring selama masa pandemi di kalangan mahasiswa pendidikan matematika: Kajian kualiatatif deskriptif. Journal of Mathematics Education and Applied, 02(01), 45-51.

Kashif, M., Aziz-Ur-Rehman, Javed, M. K., \& Pandey, D. (2020). A Surge in Cyber-Crime during COVID-19 Providing more data to websites During. Indonesian Journal of Social and Environmental Issues (Ijsei), $1(2), 48-52$.

Maisaro, A., Wiyono, B. B., \& Arifin, I. (2018). Manajement Program Penguatan Pendidikan Karakter di Sekolah Dasar. Jurnal Adminitrasi Dan Manajemen Pendidikan, 1(3), 302-312.

Mithhar, Agustang, A., Adam, A., \& Upe, A. (2021). Online Learning and Distortion of Character Education in the Covid-19 Pandemic Era. Webology, 18(November), 566-580. https://doi.org/10.14704/WEB/V18SI04/WEB18149

Obi, S. E., Yunusa, T., Ezeogueri-Oyewole, A. N., Sekpe, S. S., Egwemi, E., \& Isiaka, A. S. (2020). The Socio-Economic Impact of Covid-19 on The Economic Activities of Selected States in Nigeria. Indonesian Journal of Social and Environmental Issues (IJSEI), 1(2), 39-47. https://doi.org/10.47540/ijsei.v1i2.10

Prastitasari, H. (2021). Pembelajaran Pendidikan Karakter Di Sd Melalui Pembelajaran Pjj Pada Masa Pandemi Covid-19. Jurnal Pendidikan Kewarganegaraan, 11(01), 71. https://doi.org/10.20527/kewarganegaraan.v11i01.10577

Prihatsanti, U., Suryanto, S., \& Hendriani, W. (2018). Menggunakan Studi Kasus sebagai Metode Ilmiah dalam Psikologi. Buletin Psikologi, 26(2), 126. https://doi.org/10.22146/buletinpsikologi.38895

Putra, P., Liriwati, F. Y., Tahrim, T., Syafrudin, S., \& Aslan, A. (2020). The Students Learning from Home Experiences during Covid-19 School Closures Policy In Indonesia. Jurnal Iqra': Kajian Ilmu Pendidikan, 5(2), 30-42. https://doi.org/10.25217/ji.v5i2.1019

Santika, I. W. E. (2020). Pendidikan Karakter pada Pembelajaran Daring. Indonesian Values and Character Education Journal, 3(1), 8-19.

Selegi, S. F. (2020). Model Evaluasi Formatif-Sumatif Terhadap Motivasi Belajar Mahasiswa Pada Mata Kuliah Perencanaan Pengajaran Geografi. 20(1), 188-192. https://doi.org/10.31219/osf.io/asnjr

Septiani, A., \& Kejora, M. T. B. (2021). Edukatif: Jurnal Ilmu Pendidikan Tingkat Aktivitas Belajar Siswa pada Pembelajaran Online Pendidikan Agama Islam di Masa. 3(5), 2594-2606.

Setiawan, B., Sofyan Rofi, \& Tri Endang Jatmikowati. (2021). The Student Learning Activity Levels on the Online Learning During the Covid-19 Pandemic. Jurnal Pendidikan Islam Indonesia, 5(2), 186-197. https://doi.org/10.35316/jpii.v5i2.289

Setyosari, P. (2013). Metode Penelitian Pendidikan dan Pengembangan. Kencana.

Sopiah, C. (2021). Dampak Pembelajaran Online terhadap Pendidikan Karakter Anak Usia Dini. Journal Jendela Bunda PG PAUD UMC, 8(2), 21-31.

Sufiati, V., \& Afifah, S. N. (2019). Peran perencanaan pembelajaran untuk performance mengajar guru pendidikan anak usia dini. Jurnal Pendidikan Anak, 8(1), 48-53. https://doi.org/10.21831/jpa.v8i1.26609

Suharsaputra, U. (2012). Metode Penelitian Kuantitaif Kualitatif dan Tindakan. Refika Adhitama.

Sutisna, D., Indraswati, D., \& Sobri, M. (2019). Keteladanan Guru sebagai Sarana Penerapan Pendidikan Karakter Siswa. JPDI (Jurnal Pendidikan Dasar Indonesia), 4(2), 29.

https://doi.org/10.26737/jpdi.v4i2.1236

Edukatif : Jurnal Ilmu Pendidikan Vol 4 No 1 Tahun 2022 p-ISSN 2656-8063 e-ISSN 2656-8071 